\title{
DPP-IV Inhibitory Activity of the Ethanolic Extract of Red Gedi Leaves Abelmoschus manihot L. Medic
}

\author{
Juliet Tangka ${ }^{1,2} \mathbb{D}$, Elisabeth Natalia Barung ${ }^{2}$ D , Diana Lyrawati $^{3 *}(\mathbb{D})$, Djoko Soeatmadji ${ }^{4}$, Nurdiana Nurdiana ${ }^{5}$ \\ ${ }^{1}$ Doctoral Program of Medical Science, Faculty of Medicine, Universitas Brawijaya, Malang, Indonesia; ${ }^{2}$ Department of \\ Pharmacy, Manado Health Polytechnic, Ministry of Health, Manado, Indonesia; ${ }^{3}$ Department of Pharmacy, Faculty of Medicine, \\ Universitas Brawijaya, Malang, Indonesia; ${ }^{4}$ Department of Internal Medicine, Faculty of Medicine, Universitas Brawijaya, \\ Malang, Indonesia; ${ }^{5}$ Department of Pharmacology, Faculty of Medicine, Universitas Brawijaya, Malang, Indonesia
}

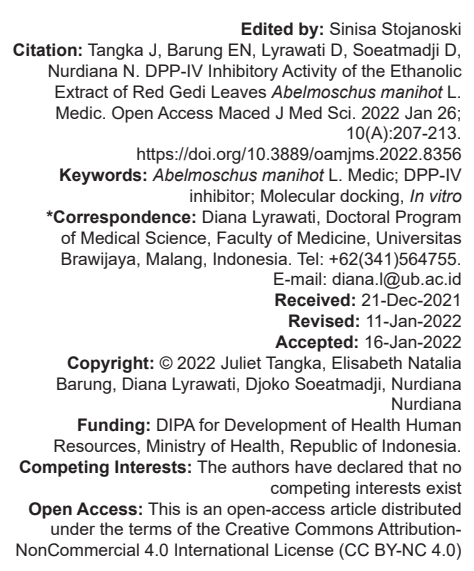

\section{Abstract}

BACKGROUND: At present, there are many drugs used to manage diabetes including dipeptidyl peptidase-4 (DPP-IV) inhibitors which target insulin secretion. Abelmoschus manihot L. Medic, an endemic species of Minahasa, Indonesia, has been used as an antidiabetic herbal medicine.

AIM: In this study, we studied its metabolites activities, in silico and in vitro, as inhibitor for DPP-IV, thus regulating insulin secretion.

RESULTS: Of 38 identified metabolites, when docked into the catalytic site DPP-IV, 10 showed good binding energy within range of the standard gliptin drugs, that is, hibiscetin, gossypentin, gossypetin - 3-glucoside, myricetin, myricetin 3-glucoside, alpha spinasterol, quercetin, syringaresinol, stigmasterol, and isoquercetin. Three of those ten metabolites showed Ki within standard drugs values, that is, gossypetin, alpha spinasterol, and stigmasterol. The profile of molecular dynamic simulation, total energy and root mean square deviation of those metabolites were all similar with the standard gliptin drugs and predicted good stability of the complexes. The subsequent in vitro assay determining DPP-IV activity of the red Gedi leaves extract demonstrated that indeed the extract inhibited DPP-IV activity with IC50 $860.67 \mu \mathrm{g} / \mathrm{mL}$. Further studies are ongoing to prove the antidiabetic properties of the whole as well as isolated single compounds of the extract in particular gossypetin, alpha spinasterol, and stigmasterol as DPP-IV inhibitors.

CONCLSION: Our in silico studies showed that the compounds of ethanolic extract of red Gedi leaves potentially serve as DPP-IV inhibitors. Based on computed binding affinity, Ki, total energy, RMSD, and stability, the most potent compounds of the extract to inhibit DPP-IV activity are probably gossypetin, alpha spinasterol, and stigmasterol.

\section{Introduction}

Diabetes Mellitus type 2 (DM2), a chronic metabolic diseases worldwide, is characterized by hyperglycemia and imbalance between insulin levels and sensitivity [1], [2]. One of the recent drugs to manage DM2 is inhibitors of dipeptidyl peptidase-4 (DPP-IV) enzyme DPP-IV enzyme is responsible for fast degradation of incretin hormones, mainly glucagon such as peptide 1 (GLP-1) and insulinotropic polypeptide (GIP). GLP-1 secreted by intestine $L$ cells facilitates blood glucose control by stimulating insulin secretion, suppressing apoptosis of and increasing proliferation of $\beta$ cells. Inhibiting DPP-IV will potentiate endogenous GLP-1 and GIP, thus, increasing insulin secretion and decreasing glucagon secretion. DPP-IV reduces postprandial and fasting hyperglycemia

The leaves extract of Abelmoschus manihot (L.) Medik, an endemic species of Minahasa, North Sulawesi, Indonesia, has been widely used as an antidiabetic herbal medicine [3], [4]. Our previous study identified 38 metabolites of ethanol extract of A. manihot (L.) Medik [5]. Based on an in silico study, although from different plant, stigmasterol and gossypetin may serve as candidates for DPP-IV inhibitor agents [6]. As now, there are not many studies addressing the antidiabetic pharmacology of the extract and its components [7], [8], [9], [10]. Phytochemicals are useful as templates or lead compounds and optimized further to generate novel, safe, and effective drugs. In this study, we predicted and determined the DDP-IV inhibitor activity of each 38 metabolites using in silico and in vitro assays. Computational molecular simulation or virtual screening aims to suggest new drug candidates by docking large libraries of small molecules into the binding site of the therapeutic target and using scoring functions to determine binding poses and estimate binding affinity. Such in silico studies make predictions about the binding affinity and selectivity of small molecules, important parameters in drug discovery and design [11]. The in silico studies have been applied and help in screening molecules for many pharmacological class of drug candidates, then the results must be assessed by in vitro assays 
before the molecules selected and examined further employing in vivo approach in pre-clinical studies.

\section{Materials and Methods}

\section{Plant material}

The leaves of red Gedi A. manihot L. Medik were collected during August 2018 from North Tondano Plantation, North Sulawesi, Indonesia. Determination of the plants was performed at the Center for Plant Conservation Botanic Gardens, Indonesian Institute of Sciences, Bogor, Indonesia (Letter B-3177/IPH.3./KS/ IX/2018 on September 18, 2018) [5].

\section{Chemicals}

Gly-pro-p-nitroanilide, tris buffer saline, sodium acetate buffer, and sitagliptin were all of pro-analytic quality from Sigma-Aldrich, and DPP-IV (derived from human placenta) from Biovision.

\section{Extraction}

Extraction of red leaves $A$. manihot (L.) Medik was performed as reported [5]. Fifty grams of dried red leaves A. manihot L. Medic extract were dynamically macerated in $96 \%$ ethanol solvent, then $500 \mathrm{~mL} 96 \%$ ethanol $(1: 10)$, stirred at $30-40^{\circ} \mathrm{C}, 200 \mathrm{rpm}$, for $6 \mathrm{~h}$. The maserate was subsequently evaporated at $50^{\circ} \mathrm{C}$ and $80^{\circ} \mathrm{C}$. The final thick extract was use for DPP-IV inhibitory assay or stored at refrigerator.

\section{Protein and ligand preparation}

Crystal structure of human DPP-IV (ID 4FFW complex control Sitagliptin) of X-Ray Diffraction with 2.9 Angstrom resolution as receptor was collected from PDB database (http://www.rcsb.org/). Identified binding sites of sitagliptin with target protein were used as standard for docking analyses. The 3D structure of 38 identified compounds of red Gedi was collected from PubChem database (https://pubchem.ncbi.nlm.nih.gov/ search/) as previously reported [5].

\section{Molecular docking}

Docking analyses of red Gedi compounds and the standard gliptins as the ligands against DPP-IV protein were carried out by using Autodock Vina PyRx 9.5 and validated using PyMol 2.3.1. The interaction of the ligand and protein DPP-IV complex as well as the binding amino acid residues with each ligand were visualized using Discovery Studio Visualizer 2017 R2 Client dan LigPlot 2.3.1. Estimation of inhibition constants (Ki) against DPP-IV of each identified red Gedi metabolites were performed on Docking Server (https://www.dockingserver.com/) with grid box coordinates according to size and center of the protein. The parameterization of the grid box was as follow docking receptor $=$ DPP-IV.pdbqt, exhaustiveness 8; num_modes 9; center_x $=20.0878578572$; center_y $=$ -8.83700476594; center_z $=54.9585865565$; size_x $=15.1426866538 ;$ size_y $=11.979308064 ;$ size_z $=$ 11.879307033; cpu $=7$.

\section{Molecular dynamics (MDs) simulation}

The strength and stability of ligand-receptor complexes (red Gedi metabolites and DPP-IV) were predicted for red Gedi compounds which showed best docking results, binding affinity, and Ki. Gliptins (sitagliptin, saxagliptin, and/or vildagliptin) were used as standards for comparison. MD was also simulated for red Gedi compounds and the standard drugs using software YASARA with setting parameters $310 \mathrm{~K}$, $\mathrm{pH} 7.4,1$ atm, observed every 25 ps (from 0 to 1000 ps), AMBER03 force field [12], [13], [14] implemented on Intel Xeon. Subsequently, root mean square deviation (RMSD) and total energy were also calculated.

\section{In vitro DPP-IV inhibitory assay}

The assay of DPP-IV inhibition activity was performed in 96 well ELISA plates. In each well, $15 \mu \mathrm{L}$ of DPP-IV enzyme, $20 \mu \mathrm{L}$ of red Gedi extract (312.5; $625 ; 1250 ; 2500 ; 5000$; and $10000 \mu \mathrm{g} / \mathrm{mL}$ ) or standard sitagliptin $(3.125 ; 6.25 ; 12.5 ; 25 ; 50 ;$ and $100 \mu \mathrm{g} / \mathrm{mL})$ and $15 \mu \mathrm{L}$ Tris-HCl buffer $(50 \mathrm{mM}, \mathrm{pH} 7.5)$ were added. The mixture was incubated at $37^{\circ} \mathrm{C}$ for $10 \mathrm{~min}$, followed by addition of $50 \mu \mathrm{L}$ Gly-pro-p-nitroanilide as the substrate, and then incubated at $37^{\circ} \mathrm{C}$ for $30 \mathrm{~min}$. The reaction was teminated with $25 \mu \mathrm{L}$ sodium acetate buffer, $\mathrm{pH}$ 4.0. The amount of $\mathrm{p}$-nitroanilide produced was measured at $405 \mathrm{~nm}$ using an ELISA plate reader. The nonenzymatic hydrolysis of substrate was corrected by measuring the increase in absorbance at $405 \mathrm{~nm}$ of control mixture without of DPP-IV enzyme. The DPP-IV inhibitory activity of each sample was calculated by the following equation: Inhibition ratio $(\%)=(1-$ [Sample OD-Blank 2 OD]/[Control OD-Blank 1 OD]) $\times$ 100. For in vitro experiments, all analyses were carried out at least in triplicates.

\section{Statistical analysis}

Means \pm standard deviations (SD) of data from in vitro DPP-IV inhibitory assay were calculated and transform into percent inhibition for each concentration tested; linear regression analyses were performed and used for $I_{50}$ calculations. All calculations were done using SPSS and MS Excel software. 


\section{Results}

\section{In silico assays}

The red Gedi compounds tested in in silico docking were malic acid; p-coumaric acid; vanilic acid; ferulic acid; caffeic acid methyl ester; syringic acid; farnesol; ficusol; hibiscone a; gmelofuran; hibiscone b; hibiscoquinone a; quercetin; moupinamide; myricetin; gossypetin; hibiscetin; $\alpha$-spinasterol; stigmasterol; aquillochin; syringaresinol; quercetin -3-o- rhamnoside; hyperin; isoquercetin; myricerol; gossypetin -3-glucoside; myricetin-3glucoside; hibiscetin-3-glucoside; daphniphyllum; kaempferitrin; sambicyanin; cyanidin-3-o-rutinoside; myriceric acid $A$; myriceric acid $B$; Boehmenan; erythro-carolignan E; hibicusin; and myriceric acid C. Among all the ligand compounds identified from red Gedi leaves extract, the binding affinity energy values between ligand and DPP-IV as receptor ranged from $-3 \mathrm{kcal} / \mathrm{mol}$ predicted for myriceric acid B up to -8.2 $\mathrm{kcal} / \mathrm{mol}$ for hibiscetin, whereas the control drugs were $-7 \mathrm{kcal} / \mathrm{mol}$ for saxagliptin and vildagliptin and $-8.6 \mathrm{kcal} / \mathrm{mol}$ for sitagliptin. Thus, based on predicted binding affinity, the top ten compounds showed binding energy close to standard drugs were hibiscetin, gossypentin, gossypetin -3-glucoside, myricetin, myricetin 3-glucoside, alpha spinasterol, quercetin, syringaresinol, stigmasterol, and isoquercetin (Table 1). The superimposed 3D diagram rendered by Pymol simulated binding site of those ten compounds and sitagliptin on the DPP-IV enzyme (Figure 1). Of those ten red Gedi metabolites, Ki values closest to that of standard drugs, Ki sitagliptin 0.48196 and vildagliptin $3.6 \mu \mathrm{M}$, were gossypentin 0.07741 , alpha-spinasterol 1.86, and stigmasterol $2.1 \mu \mathrm{M}$ (Table 1).

Table 1: Binding affinity and inhibition constant (Ki)

\begin{tabular}{lll}
\hline Ligands & Binding Affinity $(\mathrm{kcal} / \mathrm{mol})$ & $\mathrm{Ki}(\mu \mathrm{M})$ \\
\hline Sitagliptin & -8.6 & 0.48 \\
Hibiscetin & -8.2 & 541.64 \\
Gossypetin & -8 & 0.77 \\
Gossypetin 3-glucoside & -7.8 & 58.89 \\
Myricetin & -7.7 & 199.95 \\
Myricetin 3-glucoside & -7.7 & 32.95 \\
Alpha Spinasterol & -7.5 & 1.86 \\
Quercetin & -7.5 & 513.84 \\
Syringaresinol & -7.2 & 115.65 \\
Stigmasterol & -7 & 2.10 \\
Vildagliptin & -7 & 3.60 \\
Isoquercetin & -6.9 & 24.80 \\
\hline
\end{tabular}

Docking results using AutoDock Vina visualized with Discovery Studio demonstrated the intermolecular interactions along with amino acid residues involved. Interaction of the red Gedi compounds with DPP-IV (Tables 2 and 3) occurred in the vicinity of the catalytic sites involving 2 extracellular domains of DPP-IV, Ser630-Asp708-His740 of pocket/site 1 (S1) and Glu205-Glu206-Arg125 of pocket/site 2 (S2) [15]. For instance, gossypetin bound the active site of DPP-IV through van Der Waals interaction at Glu203, Ile205 of S2 DPP-IV and Tyr632, Asn711 of S1 DPP-IV, pi-cation at Arg123 of S2 DPP-IV, and conventional hydrogen bond at Glu204 of S2 DPP-IV and Ser631-His741 of S1 DPP-IV. The LigPlot results showed similar interaction, particularly hydrogen bonds at Glu204 of S2 and Ser631, Asp709, His741 of S1 DPP-IV, and hydrophobic bonds at Arg123, Glu203 of S2. Both docking and visualization software showed similar prediction for chemical interactions and that the red Gedi leaves compounds interact with DPP-IV at sites important for enzyme activity. Such interactions present steric hindrance for the DPP-IV to bind its native ligands, the incretin hormones, thus red Gedi compounds may inhibit DPP-IV activity.

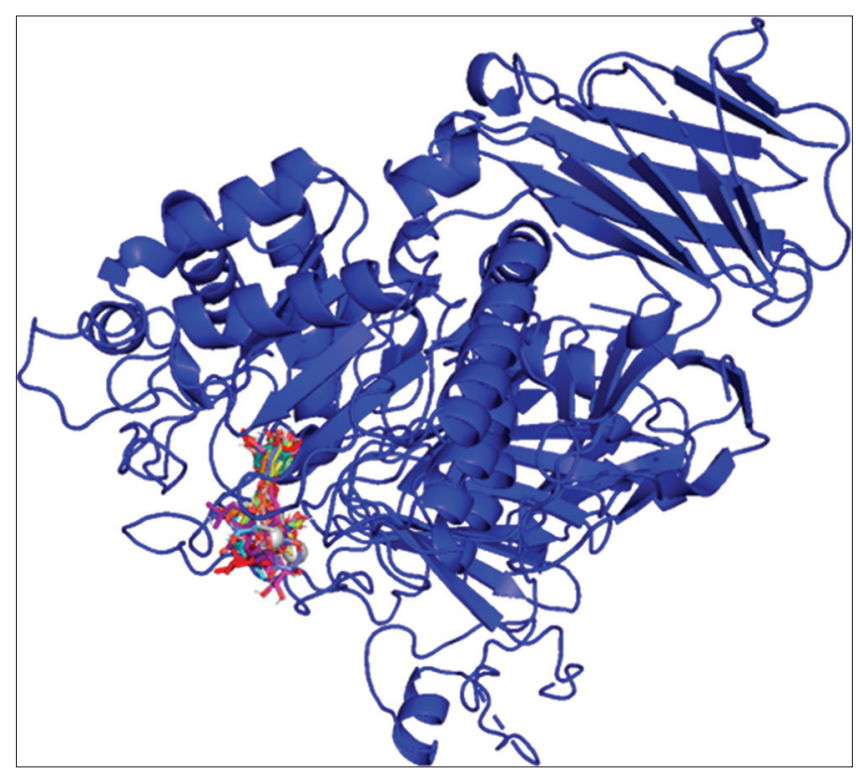

Figure 1: $3 D$ superimposed diagram of ten bioactive compounds and sitagliptin binding sites on DPP-IV enzyme. All compounds bind to catalytic domain S1 and S2 of the enzyme (blue). DPP-IV: DipeptidyI peptidase-4

The analysis of interaction between red Gedi compounds and DPP-IV depicted in Tables 2 and 3 indicated that the studied compounds have a lot of van der Waals and hydrogen bonds. Such interactions suggested that the ligands were stable within the complex with DPP-IV. The MD simulations also supported the notion of complexes stability (Figures 2 and 3). The Gedi leaves compounds, whether it has high Ki like hibiscetin or low Ki like gossypetin, were predicted to have similar total energy and RMSD patterns. The calculated structure differences at certain time points, in respect with the initial structure at the start of simulation (RMSD), indicate the stability of a protein system. The smaller the differences, the more equivalents the structures, the more stable the system [16]. Approximately at 25 ps, the Gedi leaves compounds and the gliptins achieved the stable complex with DPP-IV at total energy $-1.4 \times 10^{9} \mathrm{~kJ} / \mathrm{mol}$ and remained stable for the duration of MD simulations (1000 ps) with good RMSD values between 0.9 and 1.7 Angstrom [17]. 
Table 2: Visualization using Discovery Studio for interactions of red Gedi compounds with DPP-IV established after docking

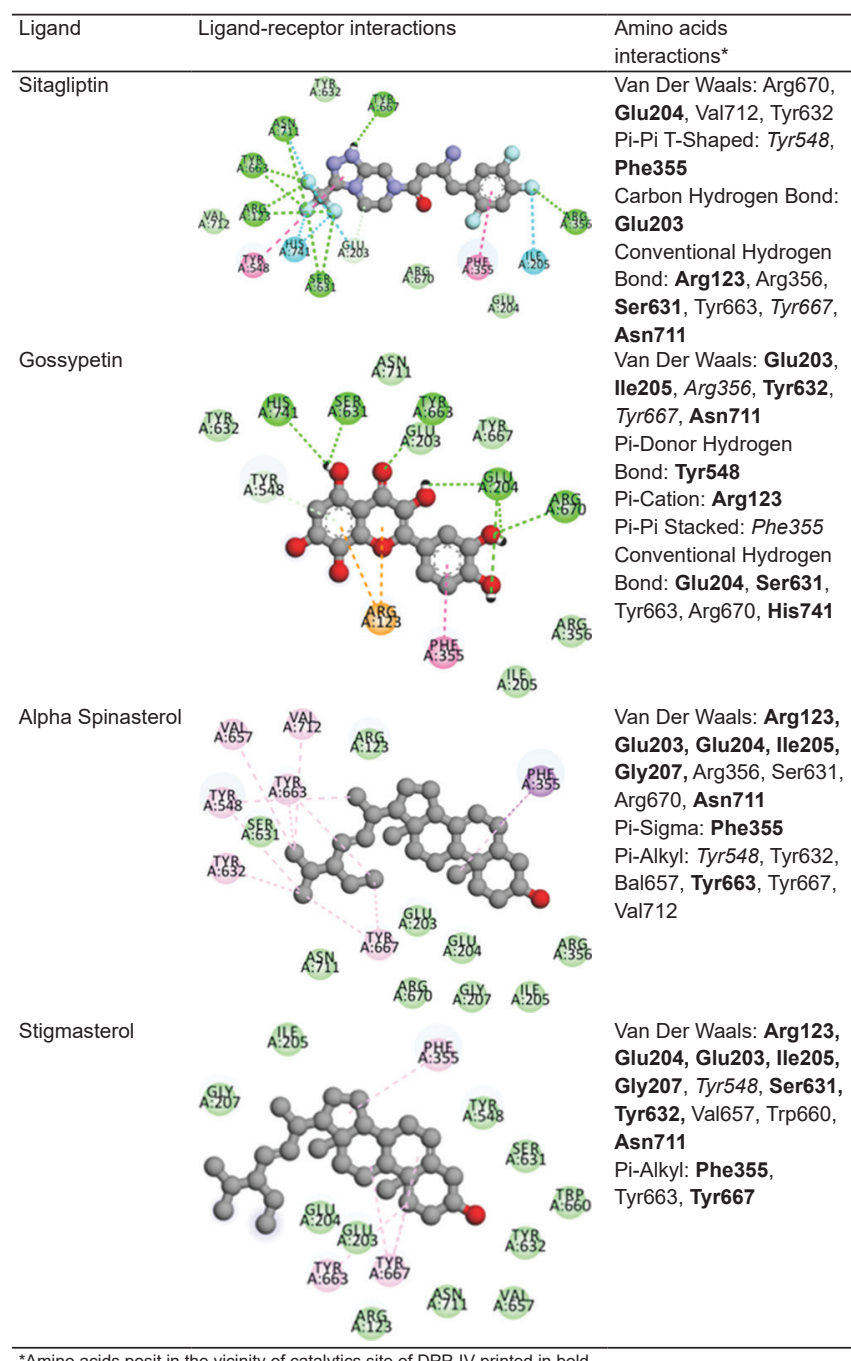

\section{In vitro DPP-IV inhibitory assays}

The ethanolic extract of red Gedi leaves A. manihot (L.) Medik was investigated for DPP-IV enzyme inhibitory activity using in vitro assays. Sitagliptin was used as the standard comparison. The experiments were replicated four times, with an excellent agreement for each replication, resulting in SD 0.00 . The results showed that the extract inhibited DPP-IV activity similar with sitagliptin at 10 times higher concentration (Table 4). The calculated $\mathrm{IC}_{50}$ of the extract was $860.87 \mu \mathrm{g} / \mathrm{mL}$, whereas $\mathrm{IC}_{50}$ of sitagliptin was $9.67 \mu \mathrm{g} / \mathrm{mL}$. The different concentration between ethanolic extract of red Gedi leaves and sitagliptin was expected. Sitagliptin is a single active pharmaceutical ingredient whereas the extract is a mix of compounds. Thus, such difference of $\mathrm{IC}_{50}$ between sitagliptin and extract can be explained by the varied potency of the active compounds and percentage of each potent DPP-IV inhibitors within the extract. From in silico studies, the most potent compounds of the extract to inhibit DPP-IV activity are probably gossypetin, alpha spinasterol, and stigmasterol.
Table 3: Visualization using LigPlot interactions between red Gedi compounds with DPP-IV

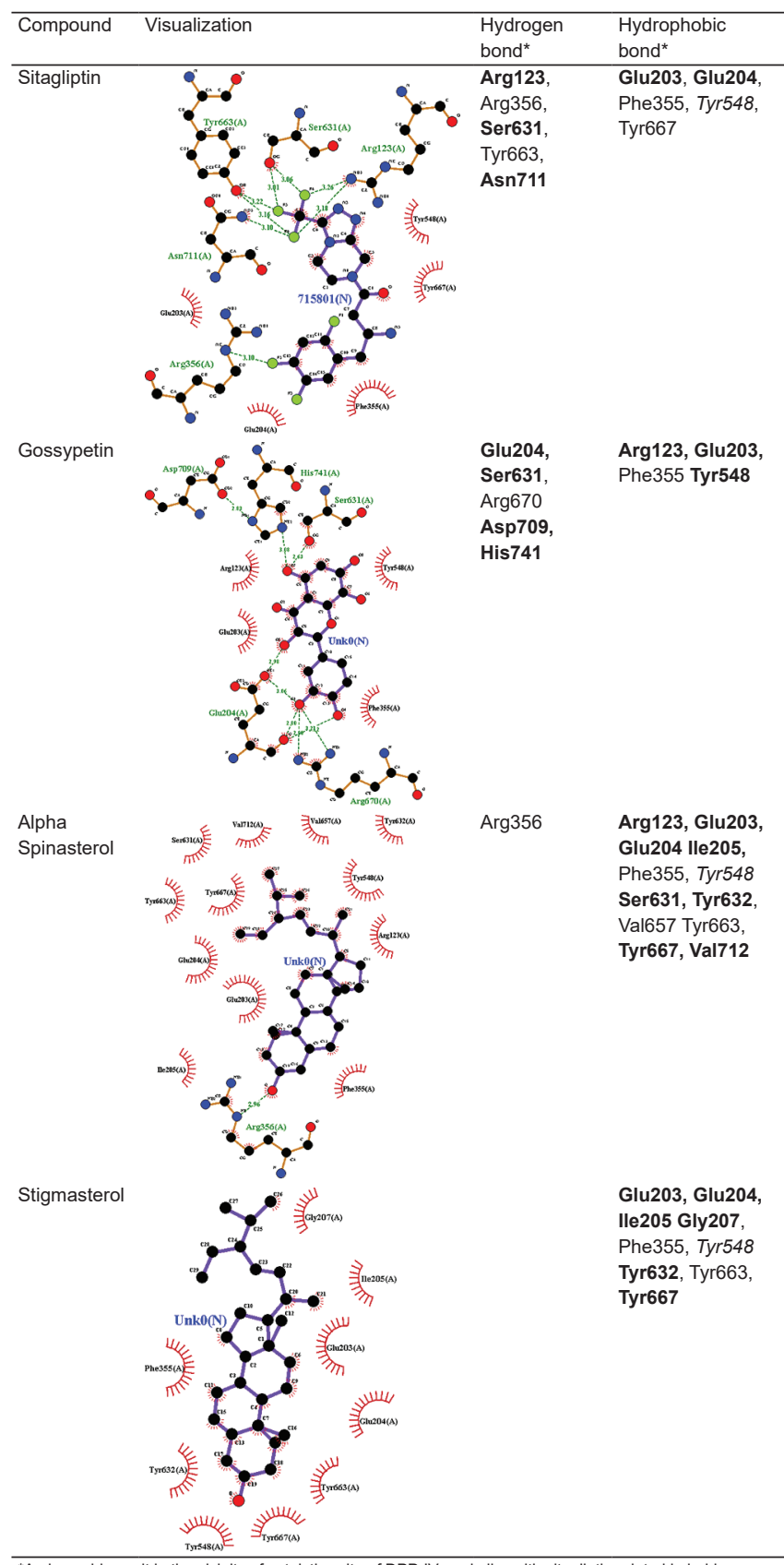

*Amino acids posit in the vicinity of catalytics site of DPP-IV or similar with sitagliptin printed in bold. DPP-IV: Dipeptidyl peptidase-4

\section{Discussion}

The results of in silico analysis demonstrated that there were three compounds of red Gedi leaves extract may serve as DPP inhibitors, that is, gossypetin, alpha spinasterol, and stigmasterol. Their binding affinity values were favorable, Ki were below $20 \mu \mathrm{M}$ [18] and closest to the values of gliptins. The interaction sites of those three compounds with DPP-IV involved amino acid residues important for recognition of native ligand and as active site of the enzyme Ser630-Asp708His740 of pocket/site 1 (S1) and Glu205-Glu206Arg125 of pocket/site 2 (S2). Additional interactions with 


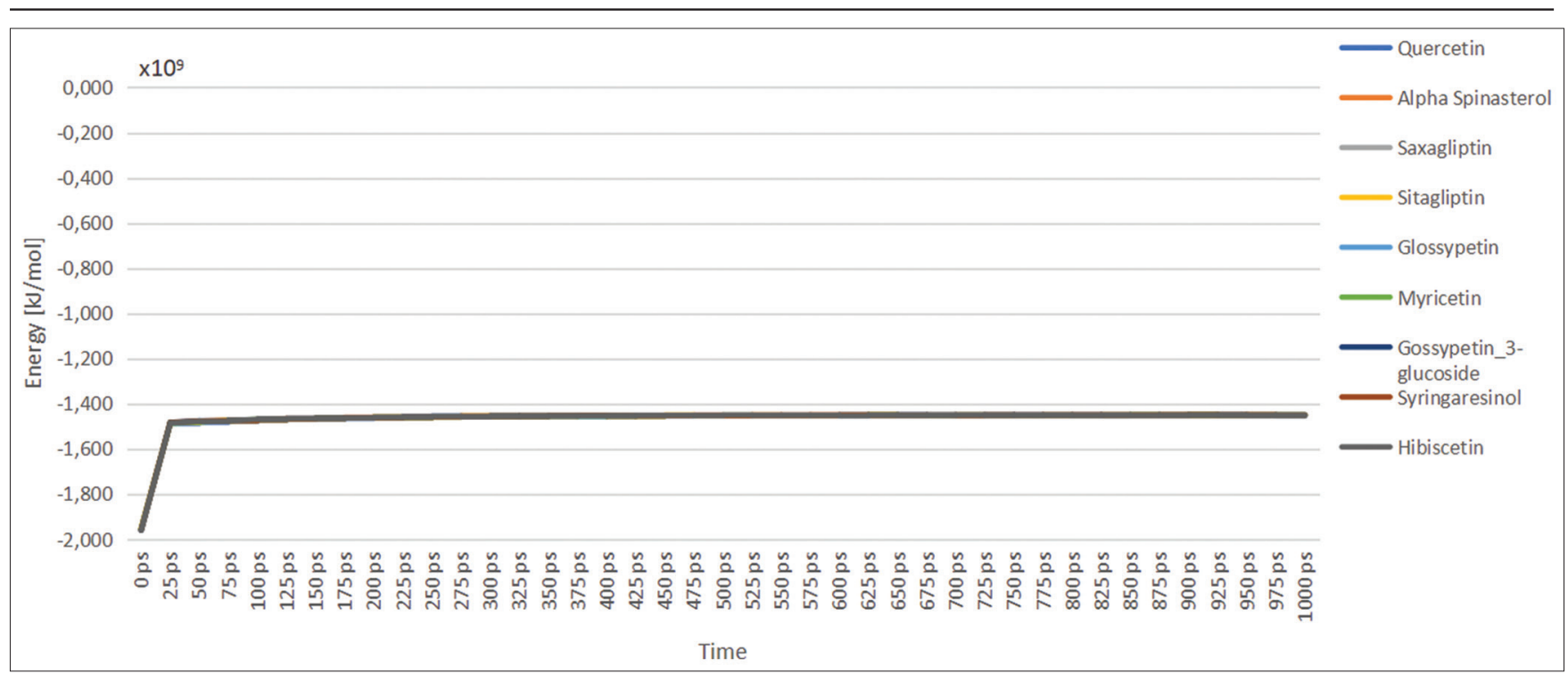

Figure 2: Total energy of red Gedi compounds with DPP-IV complexes estimated using molecular dynamic simulation. DPP-IV: Dipeptidyl peptidase-4

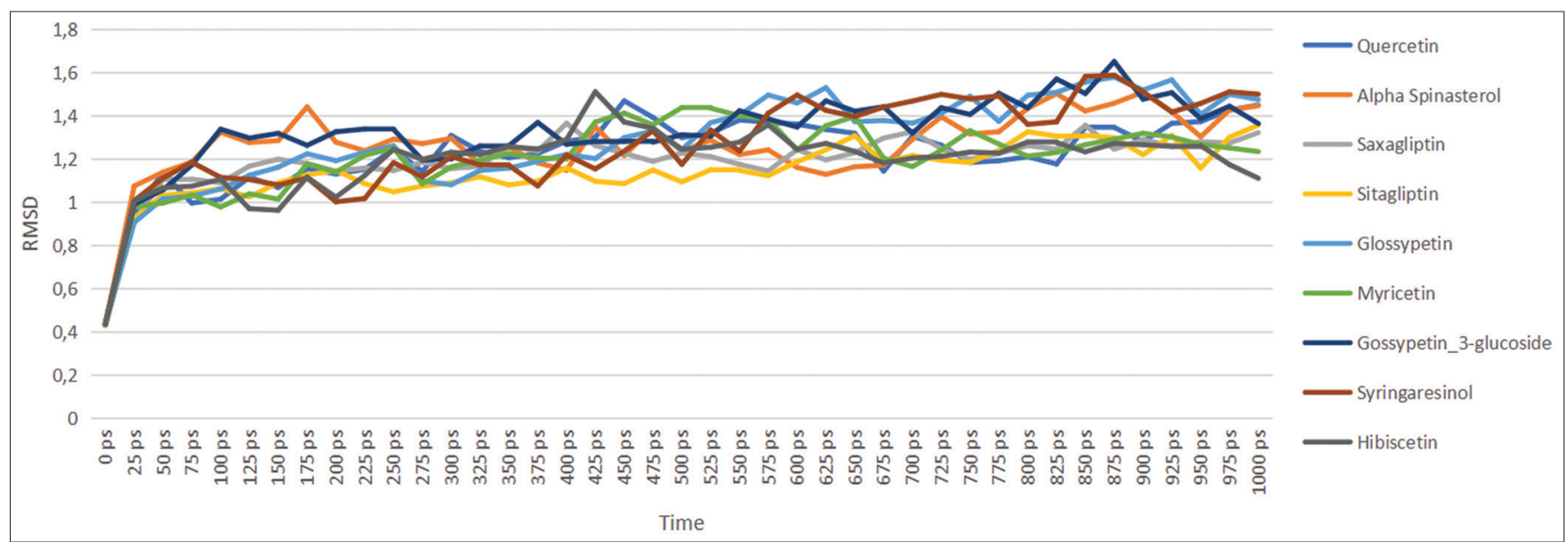

Figure 3: RMSD of red Gedi compounds with DPP-IV complexes estimated using molecular dynamic simulation at different time points. DPP-IV: Dipeptidyl peptidase-4, RMSD: Root mean square deviation

Table 4: Inhibitory effects of red Gedi leaves ethanolic exxtract on DPP-IV activity

\begin{tabular}{|c|c|c|c|c|}
\hline \multirow[t]{2}{*}{ S. No. } & \multicolumn{2}{|c|}{ Ethanolic extract of red Gedi leaves } & \multicolumn{2}{|l|}{ Sitagliptin } \\
\hline & $\begin{array}{l}\text { Concentration } \\
(\mu \mathrm{g} / \mathrm{mL})\end{array}$ & $\begin{array}{l}\text { Maximum Inhibition } \\
\pm \text { SD (\%) }\end{array}$ & $\begin{array}{l}\text { Concentration } \\
(\mu \mathrm{g} / \mathrm{mL})\end{array}$ & $\begin{array}{l}\text { Maximum Inhibition } \\
\pm \mathrm{SD}(\%)\end{array}$ \\
\hline 1. & 312.5 & $29 \pm 0.00145$ & 3.125 & $26 \pm 0.00057$ \\
\hline 2. & 625 & $54 \pm 0.00252$ & 6.25 & $35 \pm 0.00361$ \\
\hline 3. & 1250 & $60 \pm 0.00120$ & 12.5 & $64 \pm 0.00138$ \\
\hline 4. & 2500 & $75 \pm 0.00235$ & 25 & $74 \pm 0.00099$ \\
\hline 5. & 5000 & $79 \pm 0.0017$ & 50 & $78 \pm 0.00191$ \\
\hline \multirow[t]{2}{*}{6.} & 10000 & $89 \pm 0.0091$ & 100 & $88 \pm 0.00413$ \\
\hline & 860.67 & Calculated $\mathrm{IC}_{50}$ & 9.67 & Calculated $\mathrm{IC}_{50}$ \\
\hline
\end{tabular}

other sites also noticed, which may increase DPP-IV inhibition. The other binding sites identified were in the vicinity of S2 ext. (S2 extensive) subsite constructed by Val207, Ser209, Phe357, Arg358, S2 subsite Arg125, Phe357, Arg358, Glu205, Glu206, Arg669, S1 subsite Ser630, Val656, Trp659, Tyr662, Tyr666, Val711, Asn710, S1' subsite Phe357, Tyr547, Pro550, Ser630, Tyr631, Tyr666, and S2' subsite Tyr547, Trp629, Ser630, His740 [19]. Based on such interactions, the red Gedi compounds may be develop further as DPP-IV inhibitors Class 3 like sitagliptin which form interactions with the S1, S2, and S2 extensive subsites [20].

Despite the promising results from in silico analyses showing comparable interactions and potency with sitagliptin, the in vitro assays demonstrated that the red Gedi leaves extract IC ${ }_{50}$ was 100 times higher than that of sitagliptin. Such discrepancy may be explained by the nature of the crude extract which contains many compounds with different concentrations. The mixture of the compounds may act antagonistically to each other in in vitro assay for DPP-IV activity, thus, resulted in higher concentration than the single compound like sitagliptin. Another explanation is probably due to amount of the metabolites in the extract. For instance, if the total flavonoids of the ethanol extract of red Gedi leaves are minimum $23.63 \mathrm{mg} / \mathrm{g}$ extract, stated as the minimum standard of Gedi extract [21], then within $860.67 \mu \mathrm{g}$ of extract there will be $19.78 \mu \mathrm{g}$ of total flavonoid. The amount of gossypetin, a type of flavonoid, may be $<19.78 \mu \mathrm{g}$. Thus, the $\mathrm{IC}_{50}$ of gossypetin most probably 
not so different with $9.67 \mu \mathrm{g} / \mathrm{mL}$ that of sitagliptin. At present, however, amount the total flavonoid and other metabolites within the ethanolic extract of red Gedi leaves have not been determined nor published, yet. Further studies are needed to clarify, whether any interaction among metabolites, or with DPP-IV, or simply due to amount of each metabolite within extract, or else, explain the $\mathrm{IC}_{50}$ of the extract. Nevertheless, the red Gedi leaves extract can inhibit DPP-IV activity.

\section{Conclusions}

Our in silico studies showed that the compounds of ethanolic extract of red Gedi leaves potentially serve as DPP-IV inhibitors. Based on computed binding affinity, Ki, total energy, RMSD, and stability, the most potent compounds of the extract to inhibit DPP-IV activity are probably gossypetin, alpha spinasterol, and stigmasterol. In vitro assay determining the DPP-IV inhibitory activity of the extract showed that $\mathrm{IC}_{50}$ of the extract was $860.87 \mu \mathrm{g} / \mathrm{mL}$ whereas IC $_{50}$ of sitagliptin was $9.67 \mu \mathrm{g} / \mathrm{mL}$. It will be interesting to test isolated compounds, especially gossypetin, alpha spinasterol and stigmasterol, to develop new DPP-IV inhibitors while progress into antidiabetic in vivo studies of the total extracts of red Gedi leaves.

\section{Acknowledgments}

The authors would like to thank Dr. Didik Widyatmoko, M.Sc. from Center for Plant Conservation Botanic Gardens - Indonesia Institute of Sciences, Bogor, Indonesia for determination of the red Gedi leaves, Didik H. Utomo, S.Si., M.Si., from Inbio, and Fitri Armania, S.Si. Laboratory of Biomedical Science at Faculty of Medicine of Universitas Brawijaya for enabling in silico and in vitro works done. This study was funded partly by DIPA for Development of Health Human Resources, Ministry of Health, Republic of Indonesia (JT).

\section{References}

1. DeFronzo RA, Ferrannini E, Groop L, Henry RR, Herman WH, Holst JJ, et al. Type 2 diabetes mellitus. Nat Rev Dis Primers. 2015;1(1):15019. https://doi.org/10.1038/nrdp.2015.19 PMid:27189025

2. Khan MA, Hashim MJ, King JK, Govender RD, Mustafa H, Al Kaabi J. Epidemiology of Type 2 diabetes-global burden of disease and forecasted trends. J Epidemiol Glob Health.
2020;10(1):107-11. https://doi.org/10.2991/jegh.k.191028.001 PMid:32175717

3. Suoth E, Kaempe H, Tampi A. Evaluation of total polyphenol and flavonoids isolation of red gedi leaves (Abelmoschus manihot L.) (Evaluasi Kandungan Total Polifenol dan Isolasi Senyawa Flavonoid Pada Daun Gedi Merah). Chem Progress. 2013;6(2):86-91. https://doi.org/10.35799/cp.6.2.2013.3500

4. Nurrani L, Kinho J. Utilization of natural plant by the North Sulawesi community as a lowering of diabetic. In: International Conference on Forest and Biodiversity. Manado, Indonesia. Manado, Indonesia: Manado Forestry Research Institute; 2013. p. 443-52.

5. Tangka J, Barung EN, Lyrawati D, Soeatmadji DW, Nurdiana. Identification of metabolite compounds from ethanolic extract of the red gedi leaves (Abelmoschus manihot L. Medik) by LC-ESI-MS. Res J Pharm Tech. 2021. In Press.

6. Purnomo Y, Soeatmadji DW, Sumitro SB, Widodo MA. Antidiabetic potential of Urena lobata leaf extract through inhibition of dipeptidyl peptidase IV activity. Asian Pac J Trop Biomed. 2015;5(8):645-9. https://doi.org/10.1016/j.apjtb.2015.05.014

7. Fuadi A, Tangka J, Martino YA, Purnomo Y. Potency of ethanolic extract of Abelmoschus manihot (L.) Medik on kidney SOD levels and kidney MDA levels in diabetic rat model. J Bio Komplementer Med. 2020;7(2):1-8.

8. Fitriyah NY, Tangka J, Amalia Y, Purnomo Y. Effect of ethanolic extract of Abelmoschus manihot (L.) Medik on tissue tnf-alfa levels and aortic lumen diameter of diabetic rat. J Community Med. 2020;8(2):1-7.

9. Nurasidah R, Tangka J, Elyani H, Purnomo Y. Effect ethanolic extract of Abelmoschus manihot (L.) Medik on renal tumor necrosis factor alpha (TNF- $\alpha$ ) levels and glomerular epithelial cell necrosis levels in diabetic rat model. J Bio Komplementer Med. 2020;7(2):1-10.

10. Sakinah A, Tangka J, Purwanti S, Purnomo Y. Effect of ethanol extract of Abelmoschus manihot (L.) Medik on TNFalfa heart levels and total of cardiomyocyte necrosis in diabetes mellitus rats. J Bio Komplementer Med. 2020;7(2):1-9.

11. Cole DJ, Horton JT, Nelson L, Kurdekar V. The future of force fields in computer-aided drug design. Future Med Chem. 2019;11(18):2359-63. https://doi.org/10.4155/fmc-2019-0196

12. Hu Z, Jiang J. Assessment of biomolecular force fields for molecular dynamics simulations in a protein crystal. J Comput Chem. 2010;31(2):371-80. https://doi.org/10.1002/jcc.21330 PMid: 19479737

13. Tian C, Kasavajhala K, Belfon KA, Raguette L, Huang $H$, Migues AN, et al. ff19SB: Amino-acid-specific protein backbone parameters trained against quantum mechanics energy surfaces in solution. J Chem Theory Comput. 2020;16(1):528-52. https:// doi.org/10.1021/acs.jctc.9b00591

PMid:31714766

14. Case DA, Cheatham TE $3^{\text {rd }}$, Darden T, Gohlke H, Luo R, Merz KM Jr., et al. The Amber biomolecular simulation programs. J Comput Chem. 2005;26(16):1668-88. https://doi.org/10.1002/ jcc. 20290 PMid: 16200636

15. Patel BD, Ghate MD. Recent approaches to medicinal chemistry and therapeutic potential of dipeptidyl peptidase-4 (DPP-4) inhibitors. Eur J Med Chem. 2016;74:574-605. https://doi. org/10.1016/j.ejmech.2013.12.038 PMid:24531198

16. Verma D, Mitra D, Paul M, Chaudhary P, Kamboj A, Thatoi $H$, et al. Potential inhibitors of SARS-CoV-2 (COVID 19) proteases PLpro and Mpro/3CLpro molecular docking and simulation studies of three pertinent medicinal plant natural components. Curr Res Pharmacol Drug Discov. 2021;2:100038. https://doi. org/10.1016/j.crphar.2021.100038 
PMid:34870149

17. Abraham MJ, Spoel D, Lindahl E, Hess B, GROMACSDevelopment-Team. GROMACS User Manual Version 2016; 2018.

18. Mavridis L, Mitchell JBO. Predicting the protein targets for athletic performance-enhancing substances. J Cheminform. 2013;5(1):31. https://doi.org/10.1186/1758-2946-5-31 PMid:23800040

19. Arulmozhiraja S, Matsuo N, Ishitsubo E, Okazaki S, Shimano $\mathrm{H}$, Tokiwa $\mathrm{H}$. Comparative binding analysis of dipeptidyl peptidase IV (DPP-4) with antidiabetic drugs-An Ab Initio Fragment Molecular Orbital Study. PLoS One. 2016;11(11):e0166275.

\section{pone.0166275}

PMid:27832184

20. Nabeno M, Akahoshi F, Kishida H, Miyaguchi I, Tanaka Y, Ishii S, et al. A comparative study of the binding modes of recently launched dipeptidyl peptidase IV inhibitors in the active site. Biochem Biophys Res Commun. 2013;434(2):191-6. https://doi. org/10.1016/j.bbrc.2013.03.010

PMid:23501107

21. Pine TD, Alam G, Attamimi F. Quality standardisation of gedi (Abelmoschus manihot (L.) Medik) leaf extract and test of antioxidant effect with DPPH method. J Farmasi UIN Alauddin Makassar. 2015;3(3):111-28. https://doi.org/10.24252/jfuinam. v3i3.2214 